\title{
AMMI and GGE Biplot Analysis for Yield Stability of Wheat Genotypes under Drought and High Temperature Stress
}

\author{
Kirpa Ram ${ }^{1}$, Renu Munjal ${ }^{2 *}$, Hari Kesh ${ }^{2}$, Suresh $^{2}$ and Anita Kumari ${ }^{1}$ \\ ${ }^{1}$ Department of Botany and Plant Physiology, ${ }^{2}$ Department of Genetics and Plant Breeding, \\ CCS Haryana Agricultural University, Hisar INDIA \\ *Corresponding author
}

The present investigation was aimed to evaluate yield stability, environment suitability and identification of environment specific wheat genotypes using AMMI and GGE biplot analysis. Eight

\section{Keywords}

wheat, grain yield, genotype $x$ environment interaction, AMMI, GGE biplot

Article Info

Accepted:

05 April 2020

Available Online:

10 May 2020 wheat genotypes (G1-G8) with diverse genetic background were sown on three dates (TimelyNovember), (Late-December) and (Very Late-January) under drought (E1, E2, E3) and irrigated conditions (E4, E5, E6) during the Rabi seasons 2015-16 and 2016-17 in RBD with three replications at experimental farm of Wheat Section, Department of Genetics and Plant Breeding, CCS Haryana Agricultural University. Pooled analysis of variance (ANOVA) based on yield data was conducted to determine the effects of genotype $(\mathrm{G})$, environment $(\mathrm{E})$ and their interactions. The performance of wheat genotypes was assessed using stability models (1) Additive Main effects and Multiplicative Interaction (AMMI) and (2) GGE Biplot or Site Regression model. The maximum yield was observed under E4 $(525.70 \mathrm{~g} / \mathrm{m} 2)$ followed by E5 $\left(403.97 \mathrm{~g} / \mathrm{m}^{2}\right)$, E6 $(341.74 \mathrm{~g} / \mathrm{m} 2)$, E2 $\left(208.10 \mathrm{~g} / \mathrm{m}^{2}\right), \mathrm{E} 1\left(207.63 \mathrm{~g} / \mathrm{m}^{2}\right)$ and E3 $\left(169.36 \mathrm{~g} / \mathrm{m}^{2}\right)$. Among the genotypes WH $1105(393.75$ $\left.\mathrm{g} / \mathrm{m}^{2}\right)$ recorded highest grain yield followed by HD $2967\left(386.93 \mathrm{~g} / \mathrm{m}^{2}\right)$, DHTW $60\left(380.55 \mathrm{~g} / \mathrm{m}^{2}\right)$, HTW-11 (294.43 g/m2), Kundan $\left(276.60 \mathrm{~g} / \mathrm{m}^{2}\right)$, C-306 $\left(261.55 \mathrm{~g} / \mathrm{m}^{2}\right)$, WH $730\left(258.57 \mathrm{~g} / \mathrm{m}^{2}\right)$ and AKAW $3717\left(222.93 \mathrm{~g} / \mathrm{m}^{2}\right.$ ). The results showed G5 (HTW-11), G8 (WH- 1105) and G7 (WH-730) were observed to be the best adapted genotypes for E5, E3 and E2, respectively. GGE biplot analysis revealed that G4 (HD 2967) was high yielding and stable genotype for all the environments and could be recommended for its cultivation across the different environments.

\section{Introduction}

In view of global food security, identification of suitable and efficient plant type for coping with climatic changes is foremost important aspect and to address such issues, there is need of new high yielding wheat varieties that would display both high intrinsic yield stability under drought stress and the capacity to adapt to future climatic changes. By 2020, demand for wheat in marginal environments will rise in tune of $40 \%$, as compared to current levels (Rosegrant et al., 2001), thus the demand is unlikely to be met unless wheat productivity in these environments is increased (Lantican et al., 2002). It is difficult to make progress for yield and yield component traits under drought, because these 
are complex traits and highly influenced by environmental factors characterized by low heritability and large genotype-byenvironment interactions under drought conditions (Smith et al., 1990). Among many tools and techniques that have been suggested for characterizing and grouping environments, biplot analysis considered the most valuable (Yang et al., 2009).

Interpretation of performance of number of genotypes in a broad range of environments is generally affected by large $\mathrm{G} \times \mathrm{E}$ interactions (Gauch and Zobel, 1996a; Sareen et al., 2012; Tyagi et al., 2016). Main effects of analysis of variance describes the significance of the $G \times$ $E$ interaction tests but understanding of particular pattern of genotype or environment that gives rise to $\mathrm{G} \times \mathrm{E}$ interaction is not gained. Site Regression Model (SREG) is a type of linear bilinear model suitable for grouping sites and cultivars without cultivar rank change.

The model is also named as GGE (Yan et al., 2001). SREG (genotype plus $\mathrm{G} \times \mathrm{E}$ interaction) are useful for summarizing data of biplots obtained from graphing first two components of the multiplicative part (Gabriel, 1971, 1978).The objectives of experiment include; estimation of yield stability with two years of study; determining the closeness of six environments of drought conditions along with adapted wheat genotypes by using AMMI model and GGE biplot analysis.

\section{Materials and Methods}

\section{Plant material}

Eight wheat genotypes (Table 1) with diverse genetic background were evaluated under irrigated (timely sown, late sown and very late sown) and rainfed (timely sown, late sown and very late sown) conditions (Table
2). Under late sown condition, sowing was delayed by one month from the normal sowing and for very late sown condition, sowing was delayed by one month from the late sowing. The experiment was laid in a randomized block design with three replications and each genotype was allotted to four row with spacing of $22.5 \mathrm{~cm}$ apart at experimental farm of Wheat Section, Department of Genetics and Plant Breeding, CCS Haryana Agricultural University, Hisar.

The size of the plot was $2 \mathrm{~m} \times 0.94 \mathrm{~m}$. Hisar at located in global geographical position between $29.09^{\circ} \mathrm{N}$ and $75.43^{\circ} \mathrm{E}$ in western Haryana. The genotypes were grown during Rabi season in 2015-16 and 2016-17 to determine their stability for grain yield across the environments. The weather conditions data is presented in Figure 1 and 2. Seeds of the eight wheat genotypes were procured from Indian Institute of Wheat and Barley Research (IIWBR), Karnal and Wheat and Barley Section of Department of Genetics and Plant breeding, CCS Haryana Agricultural University, Hisar.

\section{Statistical analysis}

The grain yield data of wheat were subjected to pooled analysis of variance (ANOVA) to determine the effects of genotype (G), environment $(\mathrm{E})$ and their interactions. The data were graphically analyzed by using PB tools $2014 \quad$ (Version1.4, http://bbi.irri.org/products) and $\mathrm{R}$ ( $\mathrm{R}$ CoreTeam, 2012). Significance of all effects was tested against mean square of error. The performance of wheat genotypes was assessed using stability models (1) Additive Main effects and Multiplicative Interaction (AMMI) (Gauch and Zobel, 1997) and (2) GGE Biplot or Site Regression model (Yan and Kang, 2003). In GGE biplot analysis both genotypic effect $(\mathrm{G})$ and its interaction with environment (GEI) are used for the analysis 
while in AMMI model only interaction component (GEI) is used. The AMMI analysis is based on previously discovered two simple models. AMMI first analyzes the genotypes and environments main effects (additive) using analysis of variance (ANOVA) and then analyzes the residual from this model (namely the interaction) using principal components analysis (PCA). The model for AMMI analysis is given below

$\mathrm{Y}_{\mathrm{ij}}=\mu+\delta_{\mathrm{i}}+\beta_{\mathrm{j}}+\Sigma \lambda_{\mathrm{k}} \delta_{\mathrm{ik}} \beta_{\mathrm{jk}}+\varepsilon_{\mathrm{ij}}$

Where, $Y_{i j}$ is average yield of $i^{\text {th }}$ variety in the $\mathrm{j}^{\text {th }}$ environment, $\mu$ is general mean, $\delta_{\mathrm{i}}$ is the genotypic effect of ith cultivar, $\beta \mathrm{j}$ is $\mathrm{j}^{\text {th }}$ environment effect, $\lambda_{\mathrm{k}}$ is the eigen value of the Principal Component Axis $\mathrm{k}, \delta_{\mathrm{ik}}$ is the genotype eigen vector value for PC axis n, $\beta_{\mathrm{jk}}$ is the environment eigen vector value for PC axis $\mathrm{k}$ and $\varepsilon_{\mathrm{ij}}$ is the residual error.

The GGE biplot which is based on the site regression linear (SREG) bilinear model (Crossa and Cornelius, 1997; Crossa et al., 2002), displays both genotype and genotype environment variation (Kang, 1993). The graph generated by GGE biplot represents the (i) Polygon view of GGE biplot analysis of MET data, (ii) Performance of genotypes across the environments (iii) Ranking of genotypes relative to ideal genotype (iv) Relationship among test environments (v) Representativeness of test environments.

\section{Results and Discussion}

\section{Analysis of variance}

Combined analysis of variance indicated that both genotype and environment mean sum of squares were significant for grain yield (Table $3)$. This indicated the presence of variability among the genotypes and environments. The AMMI analysis of variance (Table 3) for grain yield across the environments showed that $18.47 \%$ of the total variation was attributed to genotypic effects, $75.04 \%$ to environmental effects and $6.49 \%$ to genotype $x$ environment interaction effects. The presence of GEI was clearly demonstrated by the AMMI model, indicating the substantial differences in genotypic response across the environments.

The $\mathrm{G} \times \mathrm{E}$ interaction was portioned among the first two interaction principal component axes (PCA), as they were $67.9 \%$ and $27.6 \%$ respectively; and the cumulative variance was about $95.5 \%$ for PCA I and PCA II. This implied that the interaction of the 8 wheat genotypes with six environments was predicted by the first two components of genotypes and environments.

\section{Mean performance of genotypes across the environments}

The distribution pattern of grain yield of 8 genotypes across six environments was shown in Table 4. The maximum yield was observed under E4 $\left(525.70 \mathrm{~g} / \mathrm{m}^{2}\right)$ followed by E5 $\left(403.97 \mathrm{~g} / \mathrm{m}^{2}\right)$, E6 $\left(341.74 \mathrm{~g} / \mathrm{m}^{2}\right)$, E2 $(208.10$ $\left.\mathrm{g} / \mathrm{m}^{2}\right)$, E1 $\left(207.63 \mathrm{~g} / \mathrm{m}^{2}\right)$ and E3 (169.36 $\left.\mathrm{g} / \mathrm{m}^{2}\right)$. Among the genotypes WH 1105 $\left(393.75 \mathrm{~g} / \mathrm{m}^{2}\right)$ recorded highest grain yield followed by HD $2967\left(386.93 \mathrm{~g} / \mathrm{m}^{2}\right)$, DHTW $60\left(380.55 \mathrm{~g} / \mathrm{m}^{2}\right)$, HTW-11 $\left(294.43 \mathrm{~g} / \mathrm{m}^{2}\right)$, Kundan $\left(276.60 \mathrm{~g} / \mathrm{m}^{2}\right), \mathrm{C}-306\left(261.55 \mathrm{~g} / \mathrm{m}^{2}\right)$, WH $730\left(258.57 \mathrm{~g} / \mathrm{m}^{2}\right)$ and AKAW 3717 $\left(222.93 \mathrm{~g} / \mathrm{m}^{2}\right)$.

\section{AMMI 1 biplot display}

Genotypes or environments that appear on a perpendicular line of a graph had similar mean yields and those that fall almost on a horizontal line had similar interactions (Crossa et al., 1990). Genotypes or environments on the right side of the midpoint of the perpendicular line have higher mean value than those on the left side. Results 
indicated that the genotypes G4 was high yielding and stable, G3 and G7 were unstable but high yielding (Figure 3 (a)). Genotypes, G1, G2, low yielding and may be stable, while G5 and G8 were low yielder. Environments E1, E2 and E3 were poor, while E4, E5 and E6 were rich environments.

Genotypes or environments with large PCA1 scores, either positive or negative, had large interactions, whereas genotypes with PCA1 score of zero or nearly zero had smaller interactions (Crossa et al., 1990).

The genotypes G1, G2, G4, G6 and G8 had near zero score on the first PCA1 indicating that these genotypes were less influenced by the environments (stable genotypes). Out of these, G4 registered above overall mean along with the IPCA1 score close to zero, was adjudged as the high yielding and stable genotype with general adaptation to all the environments.

\section{AMMI 2 biplot between IPAC1 vs IPAC2}

The most powerful interpretive tool for AMMI models is Bi-plot analysis. The results of AMMI 2 bi-plot (Figure 3(b) indicate the environmental scores joined to the origin by side lines. Short vectors don't exert strong interactive forces. Whereas, with long vectors exert strong interaction among each other.

The environment E6 and E5 had short vectors and they did not exert strong interactive forces while E1, E2, E3 and E4 with long vectors were more differentiating environments. The genotypes near the origin are not sensitive to environmental interaction and those distant from the origin are sensitive and have more $\mathrm{G} \times \mathrm{E}$ interactions.

In the present study, the genotypes G2 and G6 were close to the origin and hence they were non sensitive to environmental interactive forces, whereas G5, G8, G3, G4, G7 and G1 were found more responsive to environments. The best adapted genotypes for E5,E3 and E2 were found to be G5, G8 and G7 respectively.

\section{Polygon view of GGE biplot analysis of multi environment trial data}

The polygon view of the GGE biplot was constructed to show the performance of best genotypes-environment (Figure 6). A polygon was drawn on genotypes that are farthest from the biplot origin so that all other genotypes are contained within the polygon. Then perpendicular lines to each side of the polygon were drawn, starting from the biplot origin. The vertex genotype in each sector represented the highest yielding genotype in the environment that fell within that particular sector (Yan et al., 2000).

The genotypes G1, G3 and G7 had either the best or the poorest performance in one or more environments as they had the longest distance from the origin of the biplot. The equality line between G7 and G3 indicated that G7 was better in E4 and E2, whereas G3 was better in E1, E3, E5 and E6.The equality line between G3 and G1 indicated that $\mathrm{G} 3>\mathrm{G} 5>\mathrm{G} 8>\mathrm{G} 1$ in all environments.

Genotype evaluation based on GGE biplots comparison of genotypes across the environments

Vectors drawn in Figure 5 (a) shows the analyzed comparison among the genotypes in various environments. When angle between vectors of genotypes was acute $\left(<90^{\circ}\right)$, the genotypes were considered to have similar response in a particular environment, the genotypes had inverse response in the environment with obtuse angle $\left(>90^{\circ}\right)$ and if the angle was $90^{\circ}$ then genotypes were independent of each other (Yan and Tinker, 2006). In all environments performance of 
G1, G2, G6 and G8 was poor as compared to genotypes G3, G4 and G7.

\section{Ranking of genotypes relative to ideal genotype}

A model genotype is one which is high yielding over the environments and stable in its performance (Yan and Kang, 2003). Open blue circle with an arrow represents the point of average environment coordinates (AEC) for environments and dark blue dot represents the ideal genotype. The genotypes placed near the 'ideal genotype' are more desirable than others. Thus, the genotype G4 was more desirable than other (Figure 5 (b). G3 and G7 were highly variable (least stable) genotypes, whereas genotypes G4, G1 and G2 were stable genotypes. G1 and G2 were consistently the poorest. Stable genotype is desirable only when it is associated with high mean yield. In this case, G4 was observed as high yielding and stable genotype.

\section{Environment evaluation based on GGE biplots}

\section{Relationship among test environments}

In GGE biplot analysis, grouping of environments is done on the basis of angle formed between different environment vectors (Yan and Tinker, 2006). For this environmental vectors are generated by connecting the test environment to the origin of biplots by simple lines. If two environmental vectors have a right angle $\left(90^{\circ}\right)$ between them, then the two environments have no relation. A positive correlation will be present when two environments are more alike and have an angle of less than $90^{\circ}$ between the vectors; its reverse is true when the angle exceed from $90^{\circ}$ (Yan and Kang 2003). In our present study, six environments were distributed into two groups based on GGE biplot analysis
[Figure 4 (a)]. Two of our test environments; E4 and E2 were closely related as their vectors were forming an acute angle. The remaining four environments; E1, E3, E5 and E6 made another group. From this study it is clear that we should drop out four environments; one from each group as grouped environments are more alike and reduction of environments will reduce cost without losing any information (Yan and Tinker, 2006).

\section{Representativeness of test environments}

Any environment with most discriminating and representative vector i.e. vector present on AEC abscissa is considered as the most ideal teat environment (Yan, 2001). In the present study, ideal environments are represented by blue dots while open red circleare representing average environments (Figure 4b). The doted red line passing through the origin of biplot is called average environment axis (AEA) and it gives an idea of how much any test environment is representative of average environment. An environment with long vector and narrow angle with AEC is more informative and representative. On other side any test environment with short vector is less informative (Yan et al., 2007; Yan and Kang, 2003). In our study, E1 and E2 were having long vectors and thus are more discriminating environments, but these are not true representative. So testing of genotypes for specific adaptability is possible in these environments but selection for general adaptation using these environments is not valid. For such selection we can use test environment E5 which has medium vector length and narrow angle with AEC.

In the present time global population is increasing day by day. But the productivity of wheat is not increasing with the same rate due to changing environmental conditions. 
Development of varieties with higher yield potential and tolerant to different abiotic stresses is the demand of present time (Crane et al., 2011; Parry et al., 2012; Macholdt et al., 2013; Mühleisen et al., 2014; Stratonovitsch et al., 2015). Based on these problems, in the present study we have tried to identify genotypes which are stable and adaptive to varying environments. Generally selection is easy when there is no $\mathrm{GxE}$ interaction (Yan and Kang, 2003). But presence of $\mathrm{GxE}$ makes the situation more complicating. However a number of statistical methods such as Finlay and Wilkinson (1963), Perkins and Jinks (1968), Eberhart and Russell (1966), Additive main effect and multiplicative interaction model and GGE biplot analysis can be used under such situations to identify the stable genotypes. In this study, two approaches were used viz. AMMI and GGE biplot. From previous studies it is clear that AMMI is a powerful technique to measure the interaction of genotype with its environment (Crossa et al., 1990). In similar way, GGE biplot analysis is also a helpful technique for breeders as it helps indetermination of stable genotypes under multiple environments (Yan, 2001). Many earlier researchers have used these technique for evaluation of wheat genotypes under mega environments (Farshadfar et al., 2013; Rad et al., 2013; Hagos and Abay, 2013; Amiri et al., 2015; Ali et al., 2015; Kumar et al., 2016; Tekdal and Kendal, 2018).

Significant differences were observed for genotypes, environments and GE interaction (Table 2) in present study. Further it was found that environmental contribution was quite high which showed that the environments were very diverse. In contrast to our results, Farshadfar (2012) reported that environment, genotype and genotype by environment interaction contributed $27.1 \%$, $15.6 \%$ and $57.3 \%$, respectively. The contribution of genotypes, environment and genotype by environment interaction was reported to be $10.7 \%, 62.4$ and 9.80 by Hagos and Abay (2013); 2.71\%, $83.78 \%$ and 10.08 $\%$ by Akcura et al., (2011); 2.5\%, $81.2 \%$ and $16.3 \%$ by Mohammadi et al., (2015). Further partitioning of $\mathrm{GxE}$ interaction (eight genotypes across the six environments) into PCAs revealed that first PCs accounted for 67.9 and second PCs accounted for $27.6 \%$ variability in grain yield. Cumulative sum of first and second PCs accounted for $95.5 \%$ variability in grain yield.In similar experiment, Zobel et al., (1988) reported two PC which explained most of the $G \times E$ interaction. GxE interactions have been grouped into even four PCs (Crossa et al., 1990).

Estimation for stability is only valid when $\mathrm{G} x$ $\mathrm{E}$ interaction is significant (Farshadfar and Sutka, 2006; Osiru et al., 2009). In present study GxE is significant so it was further analyzed to carry out stability analysis. In this study maximum grain yield was reported from E4 while E3 was the one with minimum yield. So the data was analyzed using GGE and AMMI model. Based on AMMI analysis genotypes with lower yield than the overall mean are clustered in low PCA1 scores and are placed on the left side of the AMMI-biplot (Gauch and Zobel,1996b). Genotype G4 was located far away from origin and found stable with high mean yield. Results of present study are in conformity with Ilker et al., (2011), Bavandpori et al., (2015), Tekdal and Kendal, (2018).

Any genotype considered as idea has high mean yield and performance equally across the environments (Yan and Kang, 2003). In AMMI biplot genotypes which are closer to the mean environment and have nearly zero projections on AEC are considered as ideal (Farshadfar et al., 2012; Yan and Tinker, 2006). 
Three genotypes of present study; G4, G1 and G2 were identified as stable. But only G4 was considered best due to its high yield potentials. Similar results were also represented by Farshadfar et al., (2013). Test environments were also grouped into two distinct groups based on the analysis given by Kroonenberg, 1995; Yan, 2002; Yan and Kang, 2003. Based on the distance between any two environmental vectors environment E4 and E2 were included in group1 while environment E1, E3, E5 and E6 were included in group 2.

On the basis of the angle between two environmental vectors, the environments E4 and E2 formed one group while E3, E5, E5 and E6 formed another group. E1 and E2 were the most discriminating environments suitable for the selection of specifically adapted genotypes (Yan, 2001; Yan and Kang, 2003; Yan et al., 2007). E5 with medium vector length and small angle with AEC was found most suitable for the selection of generally adapted genotypes (Yan and Kang, 2003) Which-when-where pattern of multi-environment trials data is important for studying the possible existence of different mega-environments in a region (Gauch and Zobel, 1997; Yan et al., 2000, 2001).

A mega-environment is a growing site with homogeneous conditions that causes almost similar performance of some genotypes (Gauch and Zobel, 1996). In the which-wonwhere view of the GGE biplot (Figure3), the six environments were divided into three sectors with different winning cultivars.

Specifically, G7 was the highest yielding genotypein E4 and E2 whereas G3 was the highest yielding genotype in E1, E3, E5 and E6.

Table.1 Description of eight wheat genotypes evaluated across six environments

\begin{tabular}{|c|c|c|c|c|}
\hline $\begin{array}{c}\text { Sr. } \\
\text { No. }\end{array}$ & Genotypes & $\begin{array}{c}\text { Genotype } \\
\text { code }\end{array}$ & Pedigree & Origin \\
\hline $\mathbf{1 .}$ & AKAW 3717 & G1 & HW-2035/NI-5439 & PDKV, Akola \\
\hline $\mathbf{2 .}$ & C-306 & G2 & RGN/CSK3//2*C591/3/C217/N14//C281 & CCS HAU, Hisar \\
\hline $\mathbf{3 .}$ & DHTW-60 & G3 & IC 36761A & IIWBR, Karnal \\
\hline $\mathbf{4 .}$ & HD 2967 & G4 & ALD/COC//URES/HD2160M/HD2278 & IARI, New Delhi \\
\hline $\mathbf{5 .}$ & HTW-11 & G5 & Indigenous germplasm & IIWBR, Karnal \\
\hline $\mathbf{6 .}$ & KUNDAN & G6 & Tonari 71/NP 890 & \\
\hline 7. & WH-730 & G7 & CPAN 2092/Improved Lok I & CCS HAU, Hisar \\
\hline 8. & WH-1105 & G8 & MILAN/S87230//BABAX & CCS HAU, Hisar \\
\hline
\end{tabular}

Table.2 Description of the six environments used for evaluation of wheat genotypes

\begin{tabular}{|c|c|c|c|c|}
\hline Sr. No. & Environments & Environment code & Moisture status & Growing seasons \\
\hline $\mathbf{1 .}$ & Timely sown & E1 & Drought & $2015-16$ and 2016-17 \\
\hline $\mathbf{2 .}$ & Late sown & E2 & Drought & $2015-16$ and 2016-17 \\
\hline $\mathbf{3 .}$ & Very late sown & E3 & Drought & $2015-16$ and 2016-17 \\
\hline $\mathbf{4 .}$ & Timely sown & E4 & Irrigated & $2015-16$ and 2016-17 \\
\hline $\mathbf{5 .}$ & Late sown & E5 & Irrigated & $2015-16$ and 2016-17 \\
\hline $\mathbf{6 .}$ & Very late sown & E6 & Irrigated & $2015-16$ and 2016-17 \\
\hline
\end{tabular}


Table.3 Analysis of variance of 8 wheat genotypes tested across 6 environments

\begin{tabular}{|c|c|c|c|c|c|c|}
\hline SV & df & SS & MS & F value & \% explained & Cumulative \\
\hline Trials & 47 & 1034102.75 & 22002.19 & 11.48 & & \\
\hline Genotypes & 7 & 191024.24 & 27289.18 & 14.25 & 18.47 & 18.47 \\
\hline Environments & 5 & 776034.64 & 155206.93 & 81.02 & 75.04 & 93.51 \\
\hline $\begin{array}{c}\text { G*E } \\
\text { Interaction }\end{array}$ & 35 & 67043.87 & 1915.54 & 23.81 & 6.49 & 100 \\
\hline PCA I & 11 & 45297.77 & 4117.98 & 14.61 & 67.9 & 67.9 \\
\hline PCA II & 9 & 18435.39 & 2048.38 & 7.27 & 27.6 & 95.5 \\
\hline Pooled error & 96 & 7723.2 & 80.45 & & & \\
\hline
\end{tabular}

Table.4 Mean performance of wheat genotypes across the environments for grain yield per $\mathrm{m}^{2}$

\begin{tabular}{|c|c|c|c|c|c|c|c|c|}
\hline \multirow{2}{*}{ Sr. No. } & \multirow{2}{*}{ Genotypes } & \multicolumn{7}{|c|}{ Environments } \\
\hline & & E1 & E2 & E3 & E4 & E5 & E6 & Mean \\
\hline $\mathbf{1}$ & AKAW 3717 & 90.90 & 67.90 & 119.80 & 471.20 & 309.20 & 278.60 & 222.93 \\
\hline $\mathbf{2}$ & C-306 & 152.40 & 150.40 & 120.60 & 495.90 & 368.70 & 281.30 & 261.55 \\
\hline $\mathbf{3}$ & DHTW-60 & 215.90 & 368.60 & 245.50 & 513.80 & 504.40 & 435.10 & 380.55 \\
\hline $\mathbf{4}$ & HD 2967 & 334.20 & 322.80 & 211.60 & 580.20 & 482.60 & 390.20 & 386.93 \\
\hline $\mathbf{5}$ & HTW-11 & 148.60 & 200.40 & 165.20 & 490.20 & 393.50 & 368.70 & 294.43 \\
\hline $\mathbf{6}$ & KUNDAN & 196.40 & 159.10 & 128.90 & 503.30 & 377.00 & 294.90 & 276.60 \\
\hline $\mathbf{7}$ & WH-730 & 119.90 & 140.90 & 149.40 & 478.60 & 373.73 & 288.90 & 258.57 \\
\hline $\mathbf{8}$ & WH-1105 & 402.70 & 254.70 & 213.90 & 672.40 & 422.60 & 396.20 & 393.75 \\
\hline & Mean & 207.63 & 208.10 & 169.36 & 525.70 & 403.97 & 341.74 & 309.42 \\
\hline & C.D. & 12.52 & 20.62 & 22.91 & 35.79 & 39.13 & 24.65 & \\
\hline & SE(m) & 4.09 & 6.73 & 7.48 & 11.69 & 12.78 & 8.05 & \\
\hline & SE(d) & 5.78 & 9.52 & 10.58 & 16.53 & 18.07 & 11.38 & \\
\hline & C.V. & 3.41 & 5.61 & 7.65 & 3.85 & 5.48 & 4.08 & \\
\hline
\end{tabular}

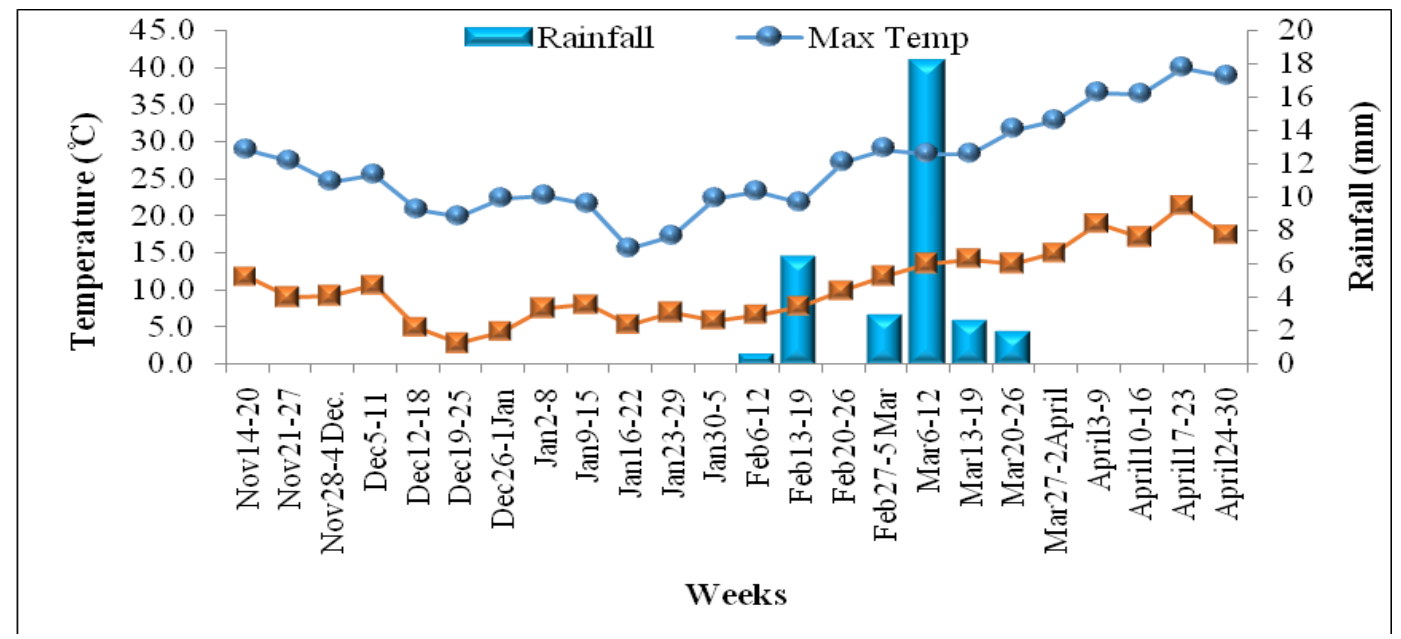

Figure.1 Weekly maximum, minimum temperature $\left({ }^{\circ} \mathrm{C}\right) \&$ rainfall $(\mathrm{mm})$ during crop seasons of 2015-16 


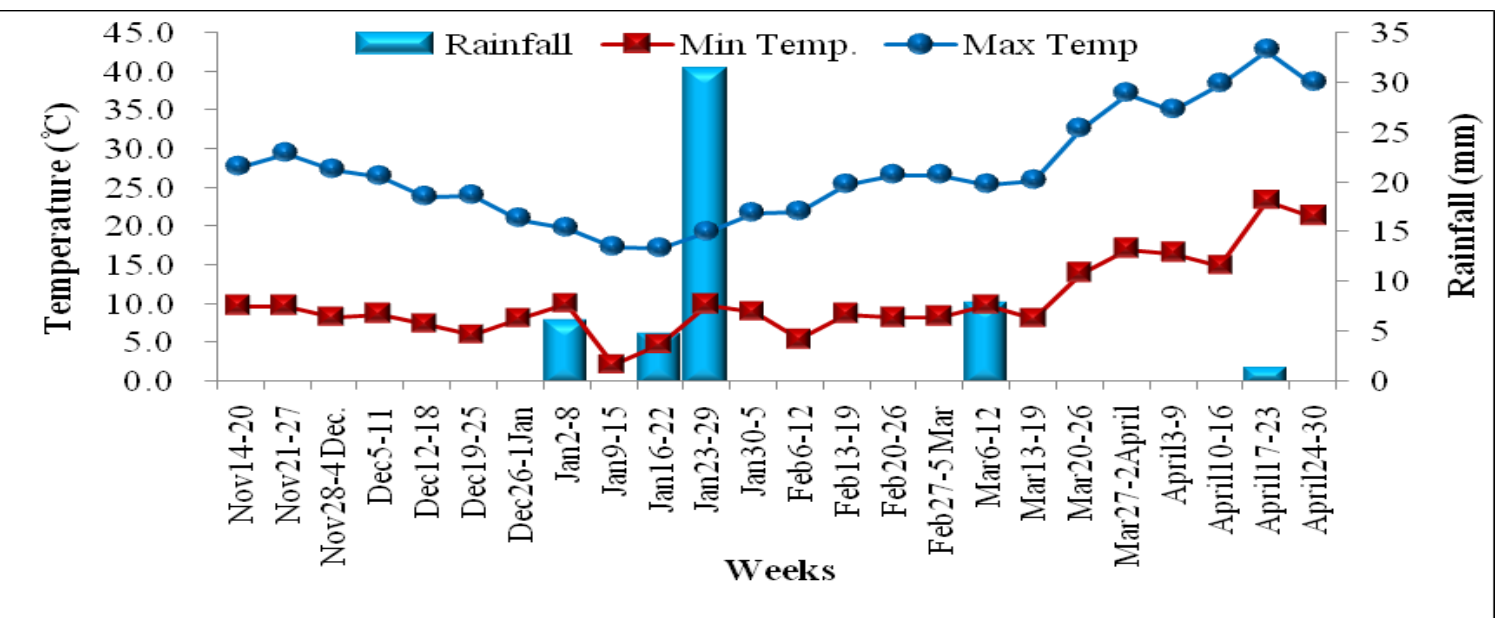

Figure. 2 Weekly maximum, minimum temperature $\left({ }^{\circ} \mathrm{C}\right)$ \& rainfall $(\mathrm{mm})$ during crop seasons of 2016-17
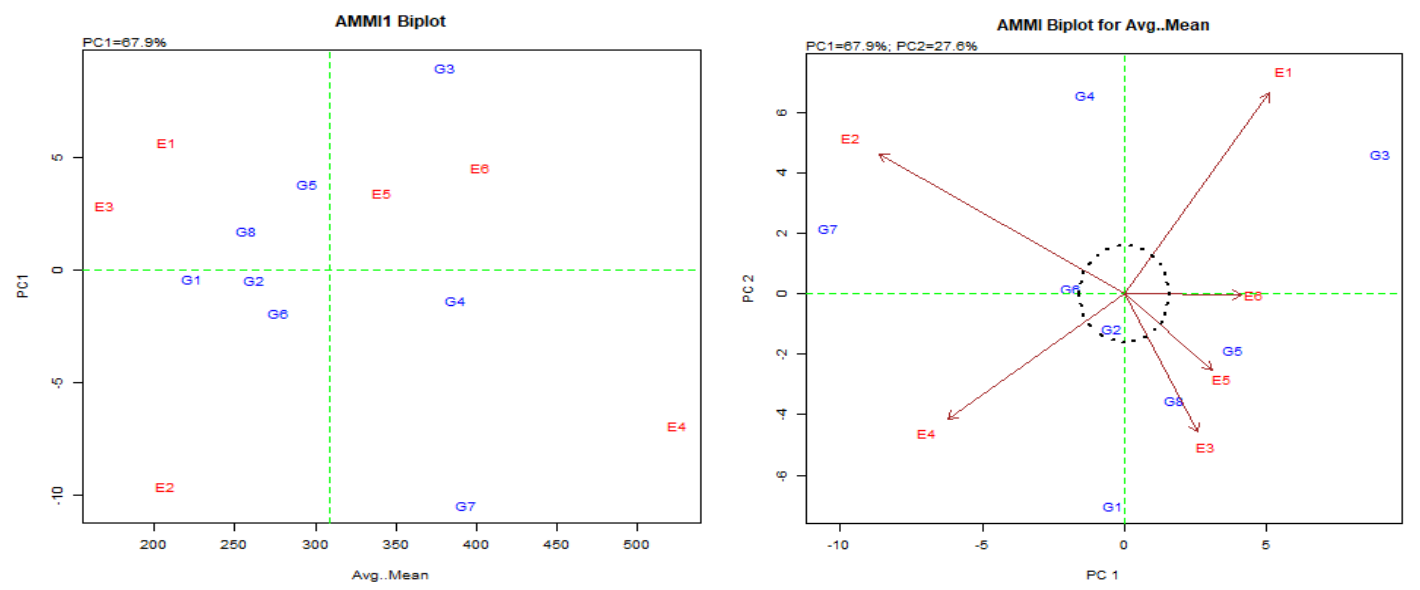

Figure.3 a) AMMI 1 Biplot for grain yield of 8 wheat genotypes and six environments using genotypic and environmental scores b) AMMI 2 Biplot for grain yield showing the interaction of IPCA2 against IPCA1 scores of 8 wheat genotypes in six environments.
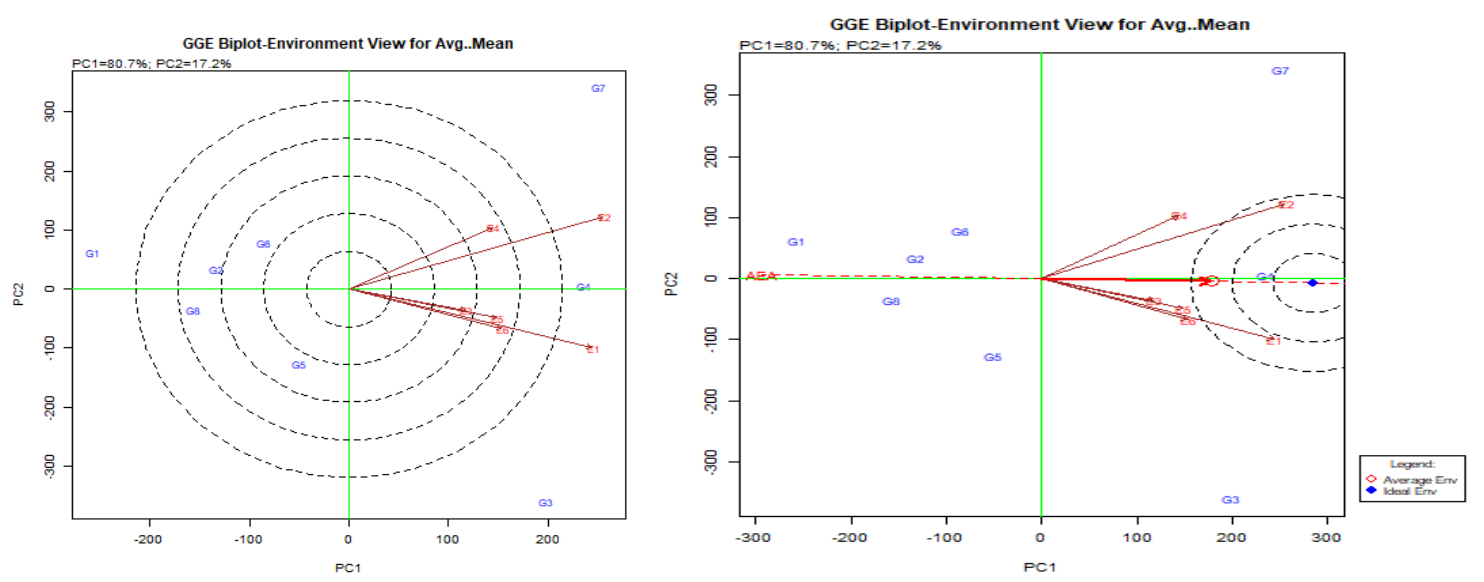

Figure.4 a) The environment view of GGE biplot to show similarities among test environments b) The discrimination and representativeness view of the GGE biplot to show the discriminating ability and representativeness the test environments 

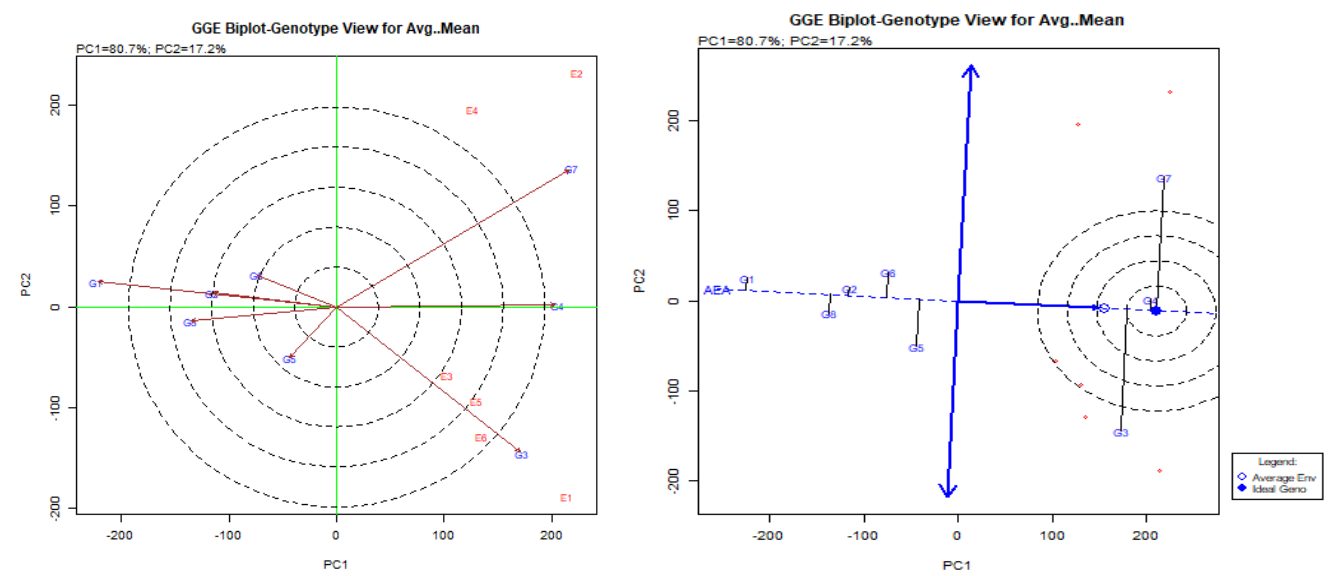

Figure.5 a) Ranking of genotyped based on the performance across the environments b) the average-environment coordination (AEC) view to rank genotypes relative to ideal genotypes.

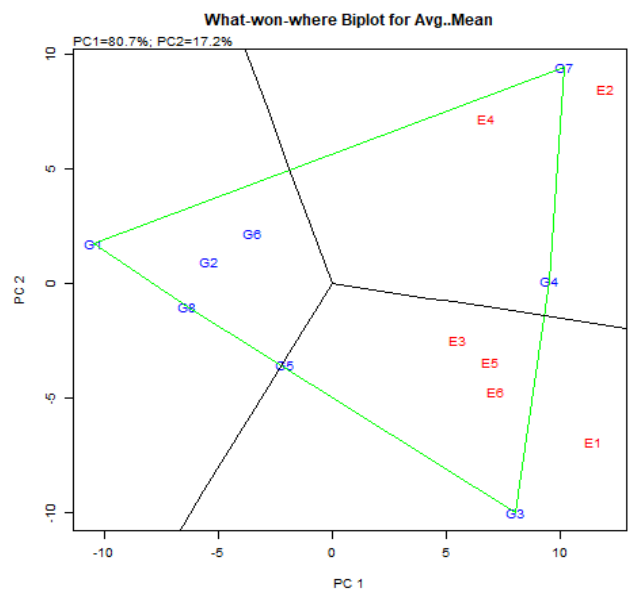

Figure.6 Polygon view of genotype-environment interaction across six test environments

Similar results were also reported by Kaya et al., (2006), Mohammadi et al., (2010), Akcura et al., (2011), Rad et al., (2013), Hagos and Abay (2013), Sabaghnia et al., (2013), Amiri et al., (2015), Kendal and Sener (2015),Abate et al., (2015), Karimizadeh et al., (2016) Alam et al., (2017), Bacha et al., (2017) and Kumar et al., (2018) in wheat.

In conclusion, stable and high yielding genotypes can be identified using AMMI and GGE biplot. Based on the performance of genotypes HD 2967 was found responsive across the environments and HTW 11 was found best responsive for timely sown drought condition as well as under irrigated very late sown condition. Genotypes HD 2967, AKAW 3717 and C 306 were found stable, whereas least stable were DHTW 60and WH 730. Best environment for the selection of genotypes was late sown environment.

\section{References}

Abate F, F Mekbib and Y Dessalegn. 2015 GGE biplot analysis of multi-environment yield trials of durum wheat (Triticum turgidum Desf.) genotypes in north western Ethiopia. American Journal of Experimental Agriculture8 (2):120-129.

AkcuraM, MTaner and Y Kaya. 2011. Evaluation of bread wheat genotypes under 
irrigated multi-environment conditions using GGE biplot analyses. Zemdirbyste 98: 35-40.

Alam MA, M Farhad, MA Hakim, NCD Barma, P.K Malaker, MMA Reza, MA Hossain and M Li..2017. AMMI and GGE biplot analysis for yield stability of promising Bread wheat genotypes in Bangladesh. Pakistan Journal of Botany49(3): 10491056.

Ali MB, AN El-Sadek, MA Sayed and MA Hassaan. 2015. AMMI biplot analysis ofgenotype $\times$ environment interaction in wheat in Egypt. Egyptian Journal of Plant Breeding 19(6): 1889-1901.

Amiri R, S Bahraminejada, S Sasani, S JalaliHonarmanda and R Fakhri. 2015. Bread wheat genetic variation for grain's protein, iron and zinc concentrations as uptake by their genetic ability. European Journal Agronomy67:20-26.

Bacha T, Z Taddesse and M Mehari. 2017. GGE biplot analysis of genotype $\mathrm{x}$ environment interaction and grain yield stability of bread wheat (Triticum aestivum L.) genotypes in Ethiopia.Biology Agriculture and Healthcare 7: 22-30.

Bavandpori F, J Ahmadi and SM Hossaini. 2015. Yield stability analysis of bread wheat lines using AMMI model. Agricultural Communication3(1), 8-15.

Crane TA, C, Roncoli and G. Hoogenboom. 2011. Adaptation to climate change and climate variability: The importance of understanding agriculture as performance. Wageningen Journal of Life Sciences57:179-185.

Crossa J and PL Cornelius.1997. Sites regression and shifted multiplicative Model clustering of cultivar trials sites under heterogeneity of variances. Crop Science 37:406-415.

Crossa J, HG Gauch and RW Zobel.1990. Additive main effect and multiplicative interaction analysis of two international maize cultivar trials. Crop Science30: 493500 .

Crossa, J., P. L. Cornelius and W. Yan. 2002. Biplots of linear-bilinear models for studying cross over genotype $\times$ environment interaction. Crop Science42: 619-633

Eberhart SA and WA Russel.1996. Stability parameters for comparing varieties. Crop Science6: 36-40.

Farshadfar E and J Sutka.2006. Biplot analysis of genotype- environment interaction in durum wheat using the AMMI model. Acta Agronomica Hungarica54: 459-467.

Farshadfar E, M Rashidi, MM, Jowkar and H Zali.2013. GGE Biplot analysis of genotype $\times$ environment interaction in chickpea genotypes. Egyptian Journal of Experimental Biology3(1):417-423.

Finlay KW and GN Wilkinson.1963. The analysis of adaptation in plant-breeding program. Australian Journal of AgriculturalResearch14:742-754.

Gabriel KR.1971. Biplot display of multivariate matrices with application to principal components analysis. Biometrika58: 453467.doi: 10.1093/biomet/58.3.453.

Gabriel KR. 1978. Least squares approximation of matrices by additive and multiplicative models. Journal of the Royal Statistical Society. Series B (Methodological)40: 186196.

Gauch HG and RW Zobel. 1997. Identifying mega-environments and targeting genotypes. Crop Science37: 311-326.

Gauch HG and RW Zobel. 1996a.AMMI analysis of yield trials. In: Kang MS, Gauch HG (eds.) Genotype by environment interaction. CRC Press. Boca Raton,FL, USA.

Gauch HG and RW Zobel. 1996b. Predictive and postdictive success of statistical analyses of yield trials. Theoretical and Applied Genetics76: 1-10. doi: 10.1007/BF00288824.

Hagos HG and F Abay.2013. AMMI and GGE biplot analysis of bread wheat genotypes in the Northern part of Ethiopia. Journal of Plant Breeding and Genetics01:12-18.

Ilker E, H Geren, R Unsal, D Sevim, AT Fatma, T Muzaffer. 2011. AMMI-biplot analysis of yield performances of breadwheat cultivars grown at different locations. 
Turkish Journal of Field Crops16(1): 6468.

Kang MS. 1993. Simultaneous selection for yield and stability in crop performance trials:consequences for growers. Agronomy Journal85: 754-757.

Karimizadeh R, A Asghari, R. Chinipardaz, O Sofalian and A Ghaffari. 2016. Application of GGE biplot analysis to evaluate grain yield stability of rainfed spring durum wheat genotypes and test locations by climatic factors in Iran. Crop Breeding Journal4: 41-49.

Kaya Y, M Akcura and S Taner. 2006. GGEbiplot analysis of multi-environment yield trials in bread wheat. Turkish Journal of Agriculture 30:325-337.

Kendal E and O Sener.2015. Examination of genotype $\times$ environment interactions by GGE biplot analysis in spring durum wheat. Indian Journal of Genetics75(3): 341-348.

Kroonenberg PM. 1995. Introduction to biplots for $\mathrm{G} \times \mathrm{E}$ tables. Department of Mathematics, Research Report \#51, University of Queensland, 22 (1995).

Kumar B, E Hooda and BK Hooda. 2018. GGE biplot analysis of multi-environment yield trials for wheat in northern India. Advances in Research16(2): 1-9.

Kumar V, AS Kharub, RPS Verma and AVerma. 2016. AMMI, GGE biplots and regression analysis to comprehend the $\mathrm{G} x$ $\mathrm{E}$ interaction in multi-environment barley trials. Indian Journal of Genetics76(2): 202-204.

Lantican MA, PL Pingali, S Rajaram. 2002. Are marginal environments catching up? In: Ekboir J (ed) CIMMYTworld wheat overview and outlook 2000-2001. Developing no-till packages for small-scale farmers. CIMMYT,Mexico, DF.

Macholdt J, G Barthelmes, F Ellmer and M Baumecker. 2013. Yield stability of winter wheat grown in Brandenburg. Journal fur Kulturpflanzen. 65: 411-421.

Mohammadi R, E, Farshadfar and A Amri. 2015. Interpreting genotype $\times$ environment interactions for grain yield of rainfed durum wheat in Iran. The Crop Journal3: 526-535.

Mohammadi R, R Haghparast, A Amri and A Ceccarelli. 2010. Yield stability of rainfed durum wheat and GGE biplot analysis of multi-environment trials. Crop and Pasture Science, 61: 92-101.

Mühleisen J, HP Piepho, HP Maurer, CFH Longin and JC Reif. 2014. Yield stability of hybrids versus lines in wheat, barley, and triticale. Theoritical and Applied Genetics 127: 309-316.

Osiru MO, OM Olanya, E Adipala, R Kapinga and B Lemaga. 2009. Yield stability analysis of Ipomoea batatus L. cultivars in diverse environments. Australian Journal Crop Science3(4): 213-220.

Parry MAJ and MJ Hawkesford. 2012. An integrated approach to crop genetic improvement. Journal of Integrative Plant Biology54: 250-259.

PB Tools, version 1.4. 2014.Biometrics and Breeding Informatics, PBGB Division, International Rice Research Institute. Los Baños, Laguna.

Perkins JM and JL Jinks. 1968. Environmental and genotype environmental component of variability.III. Multiple lines and crosses. Heredity23: 339-356.

R Core Team. 2012. R: A Language and Environment for Statistical Computing. Vienna: $\mathrm{R}$ Foundation for Statistical Computing. ISBN 3-900051-07-0.

Rad MRN, MA Kadir, MY Rafii, HZE Jaafar, MR Naghavi, and F Ahmadi. 2013. Genotype $\times$ environment interaction by AMMI and GGE biplot analysis in three consecutive generations of wheat (Triticum aestivum) under normal and drought stress conditions. AustralianJournal Crop Science 7(7): 956-961.

Rosegrant MW, MS Paisner, S Meijer and J Witcover.

2001.Global food projections to 2020:emer gingtrends and alternative futuresInternatio nal food policy research institute (IFPRI), Washington, DC. Rosegrant, Mark(2001). http://orcid.org/0000-0001-6371-6127

Sabaghnia N, R Karimizadeh and M 
Mohammadi. 2013. GGL biplot analysis of durum wheat (Triticum turgidum spp. durum) yield in multi-environment, trials. Bulgarian Journal of Agricultural Science 19: 756-765.

Sareen Sindhu, MunjalRenu, N Singh, B Singh, R Verma, BK Meena, J Shoran, Sarial Ashok and Singh Sachneet Singh. 2012. Genotype $\times$ Environment interaction and AMMI analysis for heat tolerance in wheat. Cereal Research Communications40(2): 267-276 DOI: 10.1556/CRC.40.2012.2.

Smith ME, WR Coffman, TC Baker. 1990. Environmentaleffects on selection under high and low-input conditions.In: Kang MS (ed) Genotype-by-environment interactionand plant breeding. Louisiana State University, BatonRouge, LA, USA, pp 261-27.

Stratonovitsch P and MA Semenov. 2015. Heat tolerance around flowering in wheat identified as a key trait for increased yield potential in Europe under climate change. Journal of Experimental Botany66:35993609.

TekdalS and E Kendal. 2018. AMMI model to assess durum wheat genotypes in multienvironment trials. Journal of Agricultural Science and Technology20: 153-166.

Tyagi BS, MK Singh, G Singh R Kumar, A Verma and I Sharma. 2016. Genetic variability and AMMI bi-plot analysis in bread wheat based on multi-location trials conducted under drought conditions across agro-climatic zones of India. Triticeae Genomics and Genetics7(01): 1-13.

Yan, W. 2001. GGE biplot-A Windows application for graphical analysis of multi- environment trial data and other types of two-way data. Agronomy Journal93:11111118.

Yan W and NA Tinker. 2006. Biplot analysis of multi-environment trial data: Principles and applications. Canadian Journal of Plant Science 86: 623-645.

Yan, W, LA, Hunt, Q Sheng and Z Szlavnics. 2000. Cultivar evaluation and mega environment investigation based on the GGE biplot. Crop Science40: 597-605.

Yan W, MS Kang, B Ma, S Woods and PL Cornelius. 2007. GGE biplot vs. AMMI analysis of genotype by environment data. Crop Science 47: 643-655. doi:10.2135/cropsci2006.06.0374.

Yan W.2002. Singular-value partitioning in biplot analysis of multi environment trial data. Agronomy Journal94: 990-996.

Yan W and MS Kang. 2003. GGE Biplot Analysis :a Graphical Tool for Breeders, Geneticists and Agronomists. Boca Raton,FL:CRC Press.

Yan,W, Q Sheng, YG Hu, and LA Hunt. 2001. GGE biplot-an ideal method for graphical analysis of genotype by environment interaction. Acta Agronomica Sinica 27, 21-28 (In Chinese) .

Yang, RC, J Crossa, Paul L Cornelius andJ Burgueño. 2009. Biplot Analysis of Genotype $\times$ Environment Interaction: Proceed with Caution. Crop Science 49:1564-1576.

10.2135/cropsci2008.11.0665

Zobel RW, MJ Wright and HGGauch. 1988. Statistical analysis of a yield trial. Agronomy Journal 80: 388-393.

\section{How to cite this article:}

Kirpa Ram, Renu Munjal, Hari Kesh, Suresh and Anita Kumari. 2020. AMMI and GGE Biplot Analysis for Yield Stability of Wheat Genotypes under Drought and High Temperature Stress. Int.J.Curr.Microbiol.App.Sci. 9(05): 377-389. doi: https://doi.org/10.20546/ijcmas.2020.905.043 